\title{
Debt Sustainability and Exchange Rate Stabilisation: Towards a New Theory
}

\section{Olivier Basdevant and Theuns de Wet}

Department of Economics, University of Pretoria

\begin{abstract}
The sustainability of debt is a crucial issue in developing and transitional economies. In this paper, it is showsnthat a bubble in the real exchange rate could result in a sudden collapse in the sustainability of a country's debt. Furthermore, it is shown that monetary authorities may be unable to control the exchange rate, as its dynamics also depends on that of the debt. Hence, the only feasible policy measure to stabilise the real exchange rate is to increase domestic non-price competitiveness to ensure an improvement in the trade balance of the economy.
\end{abstract}

JEL F31. F34

\section{INTRODUCTION}

This article deals with the problem of debt sustainability in developing and transitional economies, with particular emphasis on the South African economy. In most studies of debt sustainability, the problem is analysed from a long-run perspective. These studies emphasise the need to keep the rate of GDP growth equal to the real interest rate, with a balanced budget, in order to maintain a constant debt to GDP ratio (see Cuddington (1997) for a review).

This study does not analyse debt sustainability in the long run only, but also motivates the need to keep exchange rate expectations constant in the short run, especially in the case where a country's debt significantly comprises foreign debt. The change in the rate of growth of a county's debt not only depends on the interest rate or GDP growth, but also on the change in the real exchange rate. Hence, the dynamics of the exchange rate could very rapidly render debt unsustainable. The reason for this is simple: in the case of a country with significant foreign debt, a depreciation of the country's currency will increase its debt burden in terms of domestic currency. This increase in the debt burden will encourage the outflow of capital on the financial account of the balance of payments that, in turn, further increases the downward pressure on the exchange 
rate. Hence a vicious circle arises in the case where a weak currency induces a change in exchange rate expectations, which then increases the debt burden and further weakens the currency. It is therefore important that this chain of events be analysed in the short run, because it could rapidly lead to the unsustainability of a country's foreign debt (i,e. within some weeks). This could lead a country into bankruptcy even if the GDP rate of growth remains above the interest rate in the long run.

The conclusion of this article applies to transitional or developing economies that usually face difficulties in financing their public deficit by issuing domestic debt, and have to use foreign debt to finance public expenditure. In such a case, the need to keep the real exchange rate stable seems to be a prerequisite for debt sustainability and also to avoid a possible currency crisis stemming from the unsustainability of foreign debt. This of course emphasises the importance of the various measures of controlling net international reserves.

\section{THE MODEL}

In this section we derive a model of the effect of real exchange rate fluctuations on foreign debt sustainability. An accounting approach is applied to a growing economy with a debt burden consisting solely of foreign debt. In addition, one homogenous product in the economy is assumed.

\subsection{An accounting approach to sustainability}

In this section, we derive the basic properties of a very simple theoretical framework based on the accounting approach to debt sustainability. In this accounting approach the debt burden of a country is usually expressed as a ratio, usually to the gross domestic product of a country. The presentation of the model starts with an equation that expresses the growth of debt ${ }^{l}$ as a function of the nominal interest rate, debt, government expenditure, taxation and money creation:

$$
e^{n} \dot{B}=e^{n} i^{*} B+(G-T)+\dot{M}
$$

where dots represent the derivative with respect to time, and $\mathrm{e}^{\mathrm{n}}$ is the nominal exchange rate, $B$ is nominal foreign debt in domestic currency,

$i^{*}$ is nominal interest rate on the debt,

$\mathrm{G}$ is government expenditure,

$\mathrm{T}$ is the total amount of collected taxes and 
$\dot{M}$ is the creation of money by the central bank.

This model can be simplified by defining the primary surplus of the government as:

$$
S=T-G-\dot{M}
$$

and the nominal exchange rate as:

$$
\mathrm{e}^{\pi}=\frac{\mathrm{ep}}{\mathrm{p}}
$$

with e the real exchange rate, $\mathrm{p}^{*}$ a foreign price index and $\mathrm{p}$ the domestic price index.

By substituting equations 2 and 3 into equation 1 , the change in debt can be expressed as:

$$
\frac{e}{p^{*}} \dot{B}=i^{*} \frac{e}{p^{*}} B-\frac{p}{p^{*}} S
$$

or:

$$
\frac{\dot{\mathrm{B}}}{\mathrm{B}}=\mathrm{i}^{*}-\frac{\mathrm{p}}{\mathrm{e}} \frac{\mathrm{s}}{\mathrm{B}}
$$

However, because the accounting approach usually expresses debt as some ratio and because it is preferable to consider the debt to GDP ratio for a growing economy (see McCallum (1984), Hakkio and Rush (1991)), the debt is expressed as a ratio to gross domestic product. If we let $Y$ be the GDP, the debt to GDP ratio is defined by the following equation:

$$
b=\frac{e}{p^{*}} \cdot \frac{B}{Y} \text {. }
$$

From this equation it follows directly that:

$$
\frac{\dot{b}}{\mathrm{~b}}=\frac{\dot{\mathrm{e}}}{\mathrm{e}}+\frac{\dot{\mathrm{B}}}{\mathrm{B}}-\frac{\dot{\mathrm{p}}}{\mathrm{p}^{*}}-\frac{\dot{\mathrm{Y}}}{\mathrm{Y}}
$$

and by combining equations (5) to (7), the change in the growth of debt becomes:

$$
\frac{\dot{b}}{b}=r^{*}-g+\frac{\dot{e}}{e}-\frac{\bar{s}}{b}
$$

with:

$$
\begin{aligned}
r^{*} & \equiv \ddot{i}^{*}-\frac{\dot{p}^{*}}{p^{*}} \\
\bar{s} & \equiv \frac{S}{p Y}
\end{aligned}
$$


and

$$
g=\frac{\dot{Y}}{Y} .
$$

Equation 8 indicates that debt sustainability not only depends on the difference between the rate of growth of the GDP and the interest rate, but also on the rate of change in the real exchange rate.

This result can further be interpreted to show that the primary surplus required to keep the debt to GDP ratio constant over time is defined by ${ }^{2}$ :

$$
\bar{s}=b\left(r^{\cdot}-g+\frac{\dot{e}}{e}\right) \text {. }
$$

The above approach to debt sustainability can also be useful in assessing whether different government objectives are feasible or not. For example if GDP growth, as well as the primary surplus and the real exchange rate should remain constant, the debt to GDP ratio will also be constant. However, the but simple but significant result from this equation is that when debt is denominated in foreign currency, stabilising the exchange rate is a key aspect of debt sustainability. It is important because this variable is likely to be more volatile than either the GDP rate of growth or the interest rate. The importance of this result is emphasised further by the fact that the change in the real exchange rate depends crucially on exchange rate expectations. These expectations, in turn, also depend on investors' perceptions of the sustainability of the debt and more generally of the sustainability of the economic policy adopted by the government to sustain this debt. It is therefore important to investigate how economic agents form their exchange rate expectations.

\subsection{Introducing exchange rate expectations}

The previous section has described the traditional approach to analysing debt sustainability and shows how fluctuations in the real exchange rate can affect debt sustainability. A problem that may arise in a developing economy, is that the exchange rate may influence debt sustainability and in the process induce a negative feedback effect on the exchange rate. Hence debt can rapidly become unsustainable in the short run, and could lead a country into bankruptcy because of an unstable dynamic relationship that links the debt of a country and the exchange rate. The aim of this section is to analyse the conditions under which this is possible, and also the economic policy recommendations which could avoid this.

To understand the evolution of the exchange rate, one must understand how economic agents form exchange rate expectations, and then incorporate it in the 
equation defining the exchange rate. One approach that is used quite often to determine how agents form their expectations, is that of rational expectations. This approach assumes too much information on the part of agents, especially in a developing or transitional economy. Another approach that could be used, is to incorporate a learning process in building expectations. It can be assumed that agents' expectations are on average correct, but that they only have a limited set of information available. With such an approach it is possible to present expectations in a rather simple way, avoiding systematic errors in a model similar to those of Feige and Pearce (1976), Hall (1987), Hall and Garrat (1995) and (1997), in which agents are assumed to use only a univariate model to form their exchange rate expectations.

Following a range of models like Blundell-Wignall, Fahrer and Heath (1993); Tarditi (1996); Basdevant (2000) and Basdevant, Brink and Koekemoer (2000), the exchange rate is modeled as dependent on the current account deficit. The pattern of exchange rate change should, in the long run, depend on fundamentals that are derived from internal and external equilibrium (see Bayoumi, Clark, Symansky and Taylor (1994); Barrell, Anderson Lansbury and Sefton (1996) or Brink and Koekemoer (2000) for a South African application). This study focuses on external equilibrium and it is assumed that the exchange rate stabilises around a value that equilibrates the current account.

Let CUR be the current account (not including portfolio investment for simplicity). It is defined by:

$$
\mathrm{CUR}=\mathrm{TB}-\mathrm{i}^{*} \mathrm{~B}
$$

where TB is the trade balance.

Normally we could assume that exchange rate expectations depend on CUR, but we consider for simplicity that agents take into account the ratio of reserve variation over GDP, in real terms. Equation

(13) then becomes:

$$
\frac{C U R}{p^{*} Y}=\frac{T B}{p^{*} Y}-\frac{i{ }^{*} b}{e} .
$$

Let tb be the trade balance to GDP ratio:

$$
\mathrm{tb}=\frac{\mathrm{TB}}{\mathrm{p}^{4} \mathrm{Y}} .
$$

Hence, we can simply write the rule governing of expectations as the following:

$$
\frac{e}{e}=-f\left(t-\frac{i b}{e}\right)
$$


where $f(\cdot)$ is an increasing function, with $f(0)=0$. Thus, when there is an increase (decrease) in net international reserves, the exchange rate is decreasing (increasing). The dynamics of the exchange rate is then basically stable.

The dynamics of the system can be illustrated in a phase diagram. The locus where the exchange rate is constant is given by:

$$
f\left(t-\frac{i b}{e}\right)=0 \Rightarrow e=\frac{i^{*} b}{t} \text {. }
$$

We have to determine the locus where the debt to GDP ratio is constant. From equations (8) and (16) can be shown that:

$$
\frac{b}{b}=r^{*}-g-f\left(t-\frac{i b}{e}\right)-\frac{\bar{s}}{b} \text {. }
$$

Hence $b$ is constant if the following holds:

$$
e=\frac{i b}{t}+f^{-1}\left(r^{*}-g-\frac{\bar{s}}{b}\right)
$$

which defines $b$ as an increasing function of e. Comparing equations (17) and (19) shows that the locus $\dot{e}=0$ is always above the locus $b=0$. We can then construct the following phase diagram:

\section{Figure 1 Sustainable and unsustainable debt}

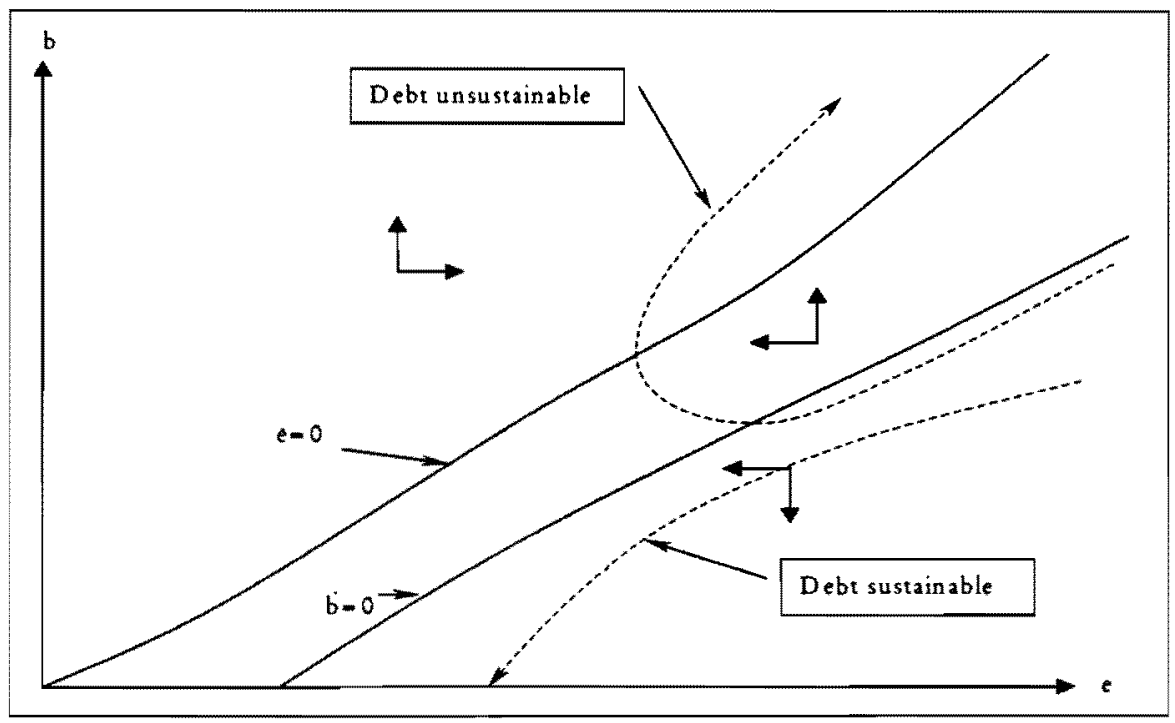




\section{ECONOMIC POLICY}

It is evident from the above theoretical analysis that a stable real exchange rate is a prerequisite for debt sustainability. This section considers some policy suggestions to avoid a sudden depreciation in a currency. According to the International Monetary Fund, global trade imbalances have increased because of the emerging market crises during the nineties. These imbalances may give rise to destabilising movements in exchange rates and may also increase protectionist pressures. These destabilising movements in the exchange rate must be prevented to ensure debt sustainability. It seems as if the only solution to this problem is to not make use of short-run monetary policies but rather to implement policies that will ensure positive trade balances in the long run.

A direct result from equation (16) is that the dynamics of the exchange rate depend on the net international reserves and, if portfolio investment is ignored, it means that it depends on the trade balance. Equation (16) has shown that the exchange rate dynamic will be stable if the trade balance is positive. More precisely, policies encouraging exports to the rest of the world should be implemented.

A traditional approach is used to analyse the trade account balance, where :

$$
\mathrm{TB}=\mathrm{f}\left(\mathrm{Y}_{-}, \mathrm{Y}_{+}^{*},{ }_{+}\right)
$$

with

$Y=$ domestic income,

$\mathrm{Y}^{*}=$ foreign income and

$\mathrm{e}=$ real exchange rate.

The signs under the variables in equation (20) show the expected direction of the effect of these variables on the trade account. Because domestic authorities cannot influence foreign income or foreign prices, the only economic variables that the domestic authorities can use to ensure a trade balance surplus are domestic income, domestic prices and the exchange rate. Although a decline in domestic income will reduce imports, this is clearly not a viable option to pursue and will have negative welfare effects and will also cause the debt to GDP ratio to rise.

This leaves the two price variables in the function to be used as policy tools. Many policy makers consider a depreciation of the exchange rate as a means to stimulate exports and discourage imports. The model and discussion in sections 2.1 and 2.2 have indicated however that this will not be an option as a policy measure because a sudden depreciation in the exchange rate could result in the 
sudden unsustainability of foreign debt when a developing economy has a substantial volume of foreign debt.

The one remaining policy tool that can be used to ensure a positive trade balance are domestic prices, which are used to stabilise the exchange rate. A decrease in domestic prices relative to foreign prices will improve the trade balance in that it will stimulate the demand for exports and reduce the demand for imports. But this is quite risky, as it may initiate a vicious circle, with a depreciating currency inducing a snow-ball effect on debt. The only sustainable policy is then to focus on structural competitiveness that will depend on goods quality, rather than their price. South Africa appears to be lagging behind its major trading partners in non-price competitiveness. There are a number of measures that can be implemented to improve this kind of competitiveness, which includes increasing the flexibility of domestic labor markets, decreasing the cost of doing business in the country and an increase in competition. Another prerequisite is an increase in measures to stimulate the supply side of the economy. An increase in investment on new and improved capital stock is necessary as well as an improvement in the technology used in the economy. Improved education and training of the labor force is also a measure that must be implemented.

The policy proposals may be summarised in stating that the only feasible policy to ensure a sustainable trade account balance and therefore a stable exchange rate, is to increase non-price competitiveness in the domestic economy. A depreciation of the exchange rate is a short-run solution only, which may cause the domestic economy's foreign debt to rapidly become unsustainable.

\section{CONCLUSION}

In this paper, we focused on the importance of keeping the exchange rate stable in order to prevent a situation where the foreign debt of a country becomes unsustainable. This conclusion was derived by applying an accounting approach to debt sustainability. The resulting model showed that, although the growth in the GDP of a country and the interest rate on debt are important factors to evaluate in determining debt sustainability, changes in the exchange rate can have such an impact on foreign debt that it could render debt unsustainable in a very short time.

The last section of the paper identifies policies that can be pursued to ensure a positive trade balance. The only feasible policy for a developing economy is to increase the non-price competitiveness of the country. Although this is a longrun policy suggestion, it will ensure a stable exchange rate, which in turn will 
ensure that the foreign debt of the developing or transitional economy will remain sustainable.

\section{ENDNOTES}

1 For simplicity we assume that there is no foreign debt.

2 This account relation can be derived from the transversal condition of the lender's utility maximisation problem (see McCallum (1984) or O'Connel and Zeldes (1988) for a growing population).

\section{REFERENCES}

1 BARRELL R; ANDERSON, B.; LANSBURY, M. and SEFTON, J. (1996) "FEERs for the NIEs. Exchange Rate Policies and Development Strategies in Taiwan, Korea, Singapore and Thailand", National Institute of Economic and Social Research: 1-42.

2 BASDEVANT, O. (2000) "An Econometric Model for the Russian Federation" forthcoming Economic Modelling.

3 BASDEVANT, O.; BRINK, S. and KOEKEMOER, R. (2000) "Modelling the South-African Exchange Rate: A Time-Varying Parameter Approach" mimeo.

4 BAYOUMI, T; CLARK, P.; SYMANSKY, S. and TAYLOR, M.P. (1994) "Robustness of Equilibrium Exchange Rate Calculations for Alternative Assumptions and Methodologies" IMF Working Paper, 17. BLUNDELL-WIGNALL, A.; FAHRER, J. and HEATH, A. (1993) "Major Influences on the Australian Dollar Exchange Rate" in A. Blundell-Wignall (ed.) The Exchange Rate, International Trade and the Balance of Payments, Conference Proceedings, Reserve Bank of Australia.

6 BRINK, S. and KOEKEMOER, R. (2000) "The Economics of Exchange Rates: A South African Model" forthcoming South African Journal of Economic and Management Sciences, 3(1): 19-51.

7 CUDDINGTON, J.T. (1997) Analysing the Sustainability of Fiscal Deficits in Developing Countries, Working Paper, Economics Department, Georgetown University, Washington D.C.

8 FEIGE, E.L. and PEARCE, D. (1976) "Economically Rational Expectations: Are Innovations in the Rate of Inflation Independent of Innovations in Measures of Monetary and Fiscal Policy ?" Journal of Political Economy 84: 499-522.

9 HALL, S.G. (1987) "A Forward-Looking Model of the Exchange Rate" Journal of Applied Econometrics, 2: 47-60. 
10 HALL, S.G. and GARRATT, A. (1995) "Model Consistent Learning: The Sterling Deutschmark Rate in the London Business School Model" Economic Modelling, 12: 87-96.

11 HALL, S.G. and GARRATT, A. (1997) "The Stability of Expectational Equilibria in the LBS Model" in Macroeconomic Modelling in a Changing World, C. Allen and S.G. Hall (eds.), John Wiley \& Sons Ltd.

12 HAKKIO, C. and RUSH, M. (1991) "Is the Budget Deficit 'Too Large'?" Economic Inquiry, 29: 429-45.

13 MCCALLUM, B. (1984) "Are Bon-Financed Deficits Inflationary? A Ricardian Analysis", Journal of Political Economy, 92: 123-35.

14 O'CONNEL, S. and ZELDES, S. (1988) "Rational Ponzi Games" International Economic Review, 29(3): 431-50. 